\title{
Spatial Variability and Distribution of the Metals in Surface Runoff in a Nonferrous Metal Mine
}

\author{
Bozhi Ren, Yangbo Chen, Guocheng Zhu, Zhenghua Wang, and Xie Zheng \\ College of Civil Engineering, Hunan University of Science \& Technology, Xiangtan 411201, China \\ Correspondence should be addressed to Bozhi Ren; 564975554@qq.com
}

Received 13 December 2015; Revised 8 February 2016; Accepted 14 February 2016

Academic Editor: Miren Lopez de Alda

Copyright (C) 2016 Bozhi Ren et al. This is an open access article distributed under the Creative Commons Attribution License, which permits unrestricted use, distribution, and reproduction in any medium, provided the original work is properly cited.

\begin{abstract}
The spatial variation and distribution features of the metals tested in the surface runoff in Xikuangshan Bao Daxing miming area were analyzed by combining statistical methods with a geographic information system (GIS). The results showed that the maximum concentrations of those five kinds of the metals ( $\mathrm{Sb}, \mathrm{Zn}, \mathrm{Cu}, \mathrm{Pb}$, and $\mathrm{Cd}$ ) in the surface runoff of the antimony mining area were lower than the standard value except the concentration of metal Ni. Their concentrations were 497.1, 2.0, 1.8, 22.2, and 22.1 times larger than the standard value, respectively. This metal pollution was mainly concentrated in local areas, which were seriously polluted. The variation coefficient of $\mathrm{Sb}, \mathrm{Zn}, \mathrm{Cu}, \mathrm{Ni}, \mathrm{Pb}$, and $\mathrm{Cd}$ was between 0.4 to 0.6 , wherein the $\mathrm{Sb}$ 's spatial variability coefficient is $50.56 \%$, indicating a strong variability. Variation coefficients of the rest of metals were less than $50 \%$, suggesting a moderate variability. The spatial structure analysis showed that the squared correlation coefficient $\left(R^{2}\right)$ of the models fitting for $\mathrm{Sb}, \mathrm{Zn}, \mathrm{Cu}, \mathrm{Ni}, \mathrm{Pb}$, and $\mathrm{Cd}$ was between 0.721 and 0.976 ; the ratio of the nugget value $\left(C_{0}\right)$ to the abutment value $\left(C+C_{0}\right)$ was between 0.0767 and 0.559 ; the semivariogram of $\mathrm{Sb}, \mathrm{Zn}, \mathrm{Ni}$, and $\mathrm{Pb}$ was in agreement with a spherical model, while semivariogram of $\mathrm{Cu}$ and $\mathrm{Cd}$ was in agreement with Gaussian model, and both had a strong spatial correlation. The trend and spatial distribution indicated that those pollution distributions resulting from $\mathrm{Ni}, \mathrm{Pb}$, and $\mathrm{Cd}$ are similar, mainly concentrated in both ends of north and south in eastern part. The main reasons for the pollution were attributed to the residents living, transportation, and industrial activities; the Sb distribution was concentrated mainly in the central part, of which the pollution was assigned to the mining and the industrial activity; the pollution distributions of $\mathrm{Zn}$ and $\mathrm{Cu}$ were similar, mainly concentrated in both ends of north and south as well as in west; the sources of the metals were widely distributed.
\end{abstract}

\section{Introduction}

The release and migration of the metals (e.g., $\mathrm{Sb}, \mathrm{Ni}, \mathrm{Cu}, \mathrm{Zn}$, $\mathrm{Cd}$, and $\mathrm{Pb}$ ) often result from the nonferrous metal mining, smelting and transportation, waste slag dumps for long-term weathering, and rain leaching. The heavy metals usually flow into mining area via surface runoff, and subsequently to local streams, rivers, lakes, and underground water. This would cause a serious heavy metal pollution to ecological environment, thus posing a potential threat to human health. Furthermore, the threat is also posed towards the sustainable development of local economy, which is dependent on the ecological environment [1-3].

The mechanism and ecological risk assessment of soil heavy metal pollution resulting from the metal mines have received considerable attention, especially in the investigation, analysis, and assessment of water environment pollution in the mining area [4-8]. However, research on the characteristics of the surface runoff pollution to the regional water environment is rare, especially on the spatial variation and the distributions of heavy metals in surface runoff. The geostatistical methods have been successfully applied to the spatial variability analyses of sand gravel content as well as the $\mathrm{pH}$ value in soil [9]. With the development of geostatistical theory, it has been successfully applied to various fields of the environmental science and a significant achievement has also been obtained [10-14]. For example, the spatial structure characteristics of the water content of soil as well as conductivity, nitrogen and phosphorus, organic matter and polycyclic aromatic hydrocarbons, metals and other pollutants, and even spatial characteristics of the pollutants in the atmospheric environment were investigated using the geostatistical methodologies. Considering the mutual penetration among disciplines and the developments of statistical 


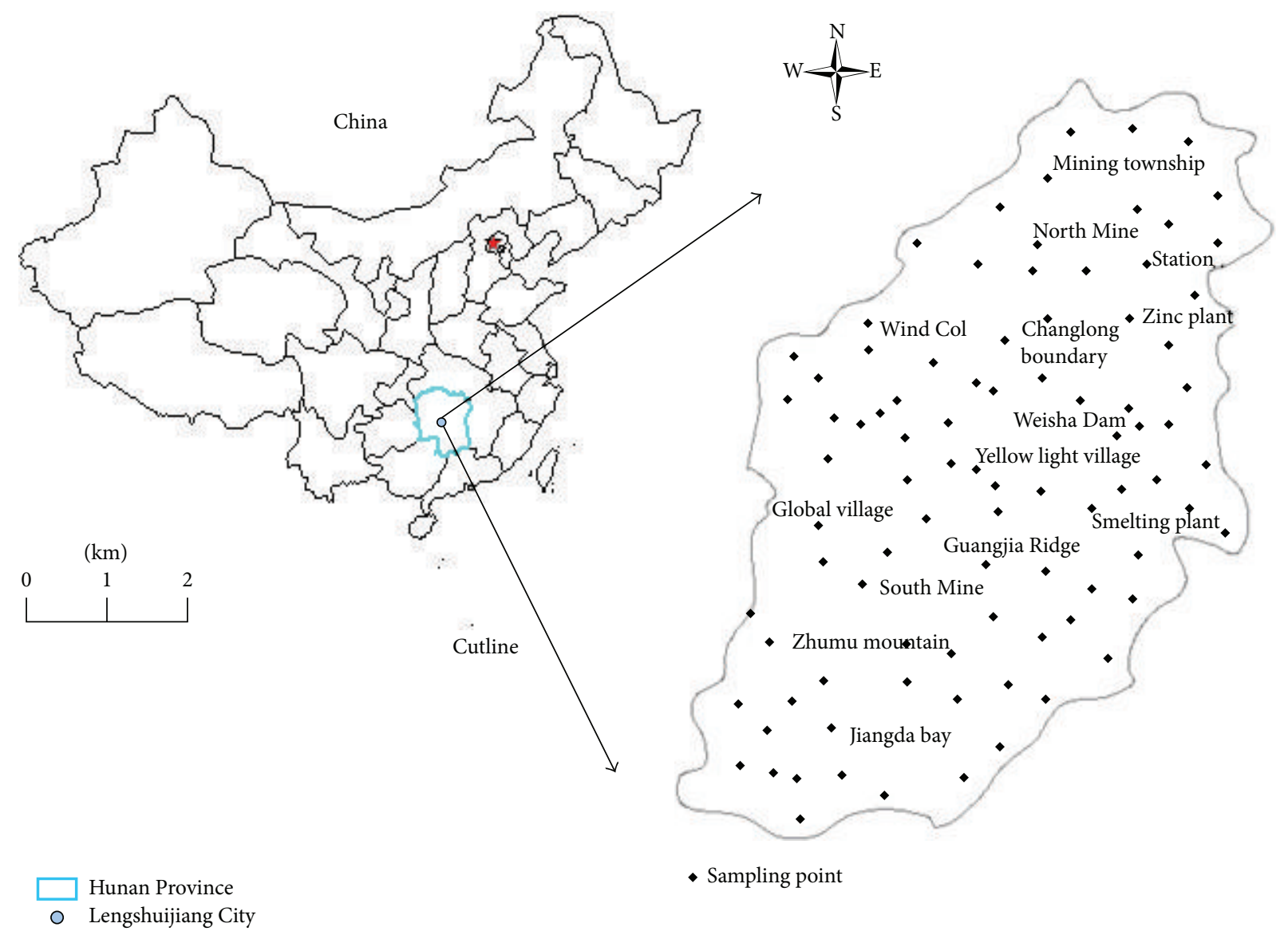

FIGURE 1: Sampling points distributions.

software and geographical information system (GIS), the statistical methods have been widely applied in the analyses of spatial variation and structural characteristics of the metal content of soil, which resulted from lake sediment, irrigation and reservoir upstream, typical mining cities and urban fringe chemical industry park, city suburbs, and urban areas $[5,15-23]$. In addition, the significant applications in the determination of metal sources have been studied. However, few studies on the spatial variation and distribution characteristics of heavy metals on surface runoff in nonferrous metal mines were reported.

In China, the mining industries have developed rapidly, among which the antimony ore mining is the most developed industry because its production capacity is the highest. However, during mine exploitation, human activities, such as mining, smelting, and transport, have led to a serious environmental pollution in antimony mine area, especially the pollution to the water environment and the residents' living, thus influencing the development of local economy. In this study, Baodaxing mining area that is located in Hunan, China, was selected as research objective. The geostatistical methods were used for the investigation of the spatial variability and the distribution characteristics of the metals within mining area in combination with GIS. This research aimed to provide a technique support of treatment of metal pollution to the water environment and of comprehensive control for antimony mining area.

\section{Materials and Methods}

2.1. Monitoring Area and Sampling. Baodaxing mining, is located in south of Tin Mine, Lengshuijiang City, Hunan, China, with geographical coordinates between $111^{\circ} 25^{\prime} 47^{\prime \prime}$ and $111^{\circ} 31^{\prime} 22^{\prime \prime}$ and longitude from $27^{\circ} 49^{\prime} 28^{\prime \prime}$ to $27^{\circ} 43^{\prime} 05^{\prime \prime}$. There are numerous low mountains and hills with altitude ranging from 300 to $600 \mathrm{~m}$ and with area up to $4.826 \mathrm{~km}^{2}$. The climate is moist with average temperature of $16.7^{\circ} \mathrm{C}$. It is cool in spring and summer while the temperature within fall and winter is relatively lower. The maximum wind speed can be up to $17 \mathrm{~m} / \mathrm{s}$. The rainy season often occurs in summer. In recent 60 years during 1949 and 2008, the average rainfall capacity is up to $1381.6 \mathrm{~mm}$. In this study, the sampling points were distributed with an interval of $0.03-0.06 \mathrm{~km}^{2}$ and there were total 94 sampling points. The distributions of sampling points are shown in Figure 1. WGS-84 and RTK instruments were used to record coordinate and elevation for each sampling point, respectively. The COORD 4.2 software was used to convert the parameters into a rectangular plane coordinate system. The experimental investigation was carried out throughout the whole year. Once the rainfall runoff occurred, 
the samples were collected from surface runoff. At each sampling point, $0.6-3 \mathrm{~L}$ water sample was collected in the polyethylene bottle, which was packed with black plastic bags and finally brought back to the lab for analysis.

2.2. Sampling. The water samples were shaken until homogeneous water samples were obtained, followed by a natural settlement of 20-30 mins. The upper nonsettlement was siphoned and filtered by $0.45 \mu \mathrm{m}$ filter membrane. The filtrate was acidified to $\mathrm{pH}<2$ via hydrochloric acid and nitric acid $[1,24]$. According to the Chinese Standard Method for Drinking Water Testing (GB5750.6-2006), the atomic absorption spectroscopy (AA7003A, Beijing Dongxi Institute of Electronic Technology) was used to measure the $\mathrm{Cu}, \mathrm{Zn}$, $\mathrm{Sb}, \mathrm{Ni}, \mathrm{Pb}$, and $\mathrm{Cd}$. For low concentration water samples, they were concentrated prior to the test. The accuracy of the method for the measurements of the metals was calibrated via standard recovery experiment.

2.3. Geostatistical Analysis. The geostatistical analysis established based on the regional variables and semivariation function is often used to investigate the distribution variation and the characteristics of pollutants in regional space [15]. The pollutant variation is defined as a variable as $Z(x) ; x$ is the position in which pollutant is located. The present work was to adopt the variation function to analyze the spatial variation and the distribution characteristics of metals in surface runoff. The variation function can be expressed as follows [25]:

$$
\gamma(h)=\frac{1}{2 N(h)} \sum_{i=1}^{N(h)}\left[Z\left(x_{i}\right)-Z\left(x_{i}+h\right)\right]^{2},
$$

where $\gamma(h)$ is the variation function; $h$ is the step length $(\mathrm{m}) ; N(h)$ is the number of those sampling points where the distance between samples is equal to $h ; Z\left(x_{i}\right)$ and $Z\left(x_{i}+h\right)$ are measured pollutant values $(\mathrm{mg} / \mathrm{L})$ at $x_{i}$ and $x_{i}+h$, respectively.

In geostatistical analysis, semivariation function contains the models without/with partial sill values. The Gauss model, spherical model, and exponential model belong to those with partial sill value. The most used model is spherical model, followed by Gauss model and exponential model. The Gauss model, spherical model, and exponential model are expressed using the following forms:

Spherical model:

$$
\gamma(h)= \begin{cases}0, & h=0, \\ C_{0}+C\left(\frac{3 h}{2 a}-\frac{h^{3}}{2 a^{3}}\right), & 0<h \leq a, \\ C_{0}+C, & h>a .\end{cases}
$$

Gauss model:

$$
\gamma(h)= \begin{cases}0, & h=0, \\ C_{0}+C\left(1-e^{-h^{2} / a^{2}}\right), & h>0 .\end{cases}
$$

Exponential Model:

$$
\gamma(h)= \begin{cases}0, & h=0, \\ C_{0}+C\left(1-e^{-h / a}\right), & h>0,\end{cases}
$$

where $a$ is a range march of which value corresponds to $x$ axis, standing for spatial self-correlation in investigated range. A larger $a$ value implies a larger spatial self-correlation range; $C_{0}$ is nugget value (semivariance given distance is zero); $C$ is partial sill, standing for the variation from natural factors of landform, climate, and soil; $C_{0}+C$ is partial sill value (it is $\gamma(h)$ value under condition that the half-square difference tends to be stable, corresponding to the variable $a$ ), presenting the total variation of this variable in the variable range; in general, $C_{0} /\left(C_{0}+C\right)$ can be used to describe spatial correlation degree of specific variable in variable range. The ratio less than $25 \%$ means that the variable has a very strong spatial correlation, while that between $25 \%$ and $75 \%$ illustrates that it may have a moderate spatial correlation; however, beyond $75 \%$ it implies relatively weak spatial correlation [26].

2.4. Data Analysis. In this study, a scientific software (SPSS 19.0) was used in basic statistical analysis, normal distribution, and frequency analysis of the measured data. The Grubbs test method was used to remove the abnormal data from group. The normal distribution of the measured data was analyzed by Kolmogorov-Smirnov method [25, 27-30]. According to (1), the variation function was calculated using GS+V9.0 software. With the effective lag distance of $2 \mathrm{~km}$ and an acceptability angle of $22.5^{\circ}$, the fitting of the semivariance functions at different orientations $\left(0^{\circ}, 45^{\circ}, 90^{\circ}\right.$, and $\left.135^{\circ}\right)$ via Suffer 8.0 was carried out, which was used to analyze spatial variation of $\mathrm{Ni}, \mathrm{Cu}, \mathrm{Sb}, \mathrm{Cd}, \mathrm{Zn}$, and $\mathrm{Pb}$ in surface runoff in the mining area. With the Kriging interpolation method in the ArcGIS 10.2, the spatial distribution of the above metals can be effectively analyzed [28].

\section{Results and Discussion}

3.1. Standard Recovery Experiment. The standard recovery experimental results are shown in Table 1. From Table 1, the recovery rate of $\mathrm{Sb}, \mathrm{Ni}, \mathrm{Cu}, \mathrm{Zn}, \mathrm{Cd}$, and $\mathrm{Pb}$ were between $97.8 \%$ and $101.2 \%$, which indicated that the measurement method of the metal samples utilized in this study was accurate and reliable.

3.2. Basic Statistical Analysis of Heavy Metals in Surface Runoff. A comparison between the detection results of 94 samples from the investigated area and the metal index shown in the drinking water standard testing method (GB5750.62006) was made via SPSS software analysis. The results are shown in Table 2 and Figure 2.

It showed that the contents of $\mathrm{Sb}, \mathrm{Zn}, \mathrm{Cu}, \mathrm{Ni}, \mathrm{Pb}$, and $\mathrm{Cd}$ in the surface runoff in the study area were in the range of 0.1315 to $2.4853 \mathrm{mg} / \mathrm{L}, 0.9161$ to $2.0209 \mathrm{mg} / \mathrm{L}, 0.0403$ to $1.7534 \mathrm{mg} / \mathrm{L}$, 0.0001 to $0.0143 \mathrm{mg} / \mathrm{L}, 0.0001$ to $0.2220 \mathrm{mg} / \mathrm{L}$, and 0.0001 to $0.1105 \mathrm{mg} / \mathrm{L}$, respectively. The difference between the maximum and the minimum of each element was relatively high. 


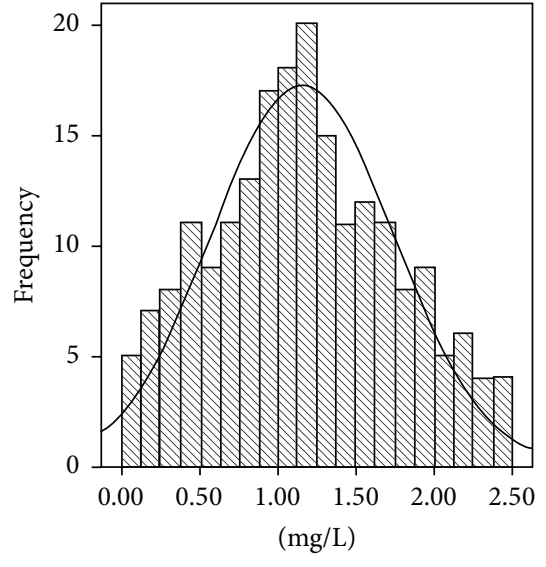

$\mathrm{Sb}$

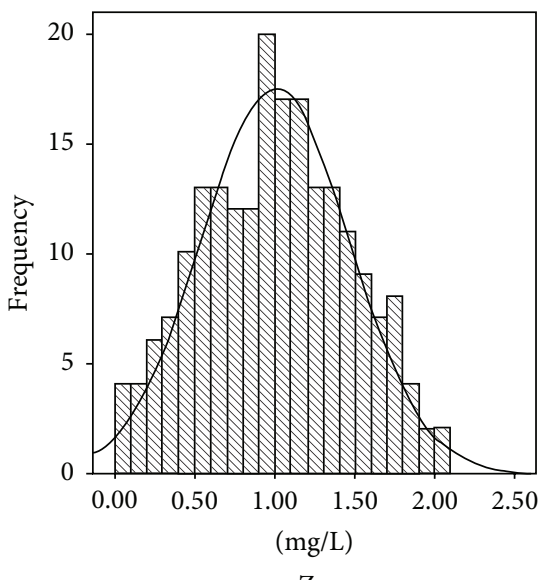

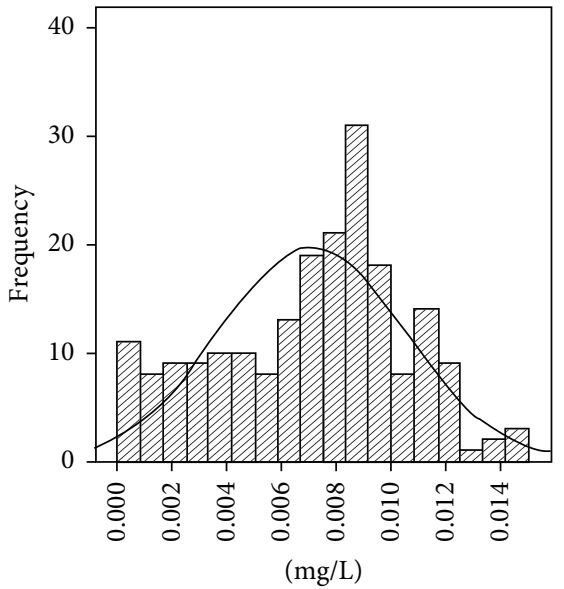

$\mathrm{Ni}$

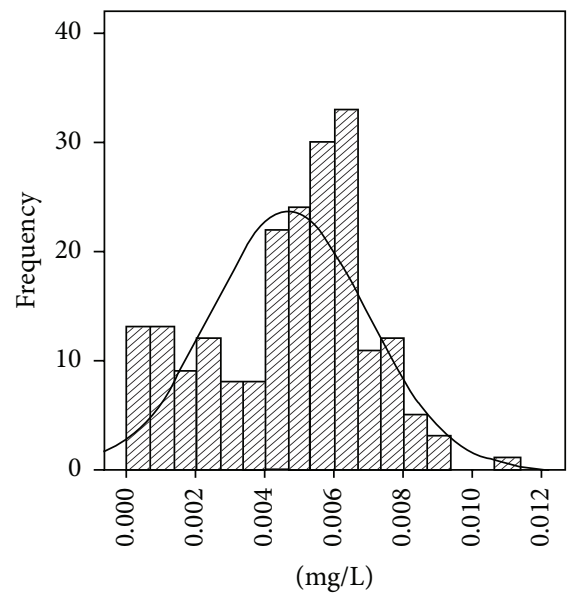

Cd
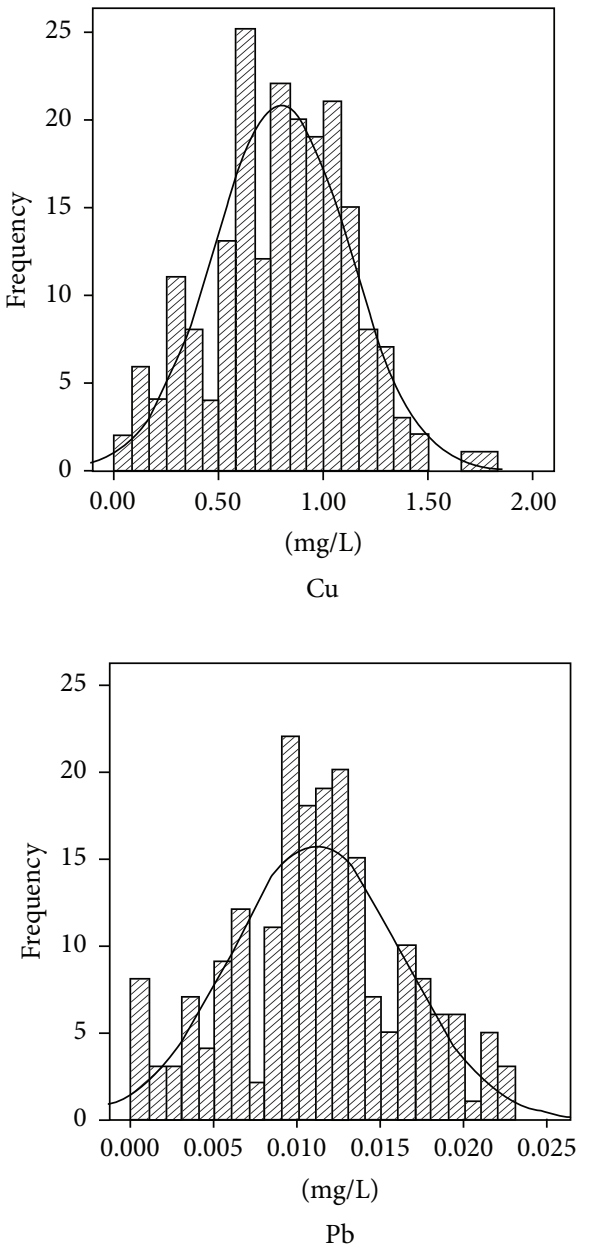

FIgUre 2: Frequency distributions of $\mathrm{Sb}, \mathrm{Ni}, \mathrm{Cu}, \mathrm{Zn}, \mathrm{Cd}$, and $\mathrm{Pb}$ in surface runoff in antimony mine.

TABLE 1: The samples recovery rate of standard recovery experiment.

\begin{tabular}{lcccc}
\hline \multirow{2}{*}{ Heavy metal } & \multicolumn{3}{c}{ Content $(\mathrm{mg} / \mathrm{L})$} & \multirow{2}{*}{ Recovery rate (\%) } \\
& Before & With scalar & After & \\
\hline $\mathrm{Sb}$ & 1.1031 & 0.5000 & 1.6021 & 99.8 \\
$\mathrm{Zn}$ & 0.9930 & 0.5000 & 1.4875 & 98.9 \\
$\mathrm{Cu}$ & 0.6598 & 1.0000 & 1.6718 & 101.2 \\
$\mathrm{Ni}$ & 0.0061 & 1.0000 & 1.0071 & 100.1 \\
$\mathrm{~Pb}$ & 0.1867 & 1.5000 & 1.6792 & 99.5 \\
$\mathrm{Cd}$ & 0.0895 & 1.5000 & 1.5565 & 97.8 \\
\hline
\end{tabular}

This showed that the six kinds of metals had an accumulation. As seen from the maximum and the standard values, except the maximum value of $\mathrm{Ni}$ lower than standard value, the maximum values of other five metals ( $\mathrm{Sb}, \mathrm{Zn}, \mathrm{Cu}, \mathrm{Pb}$, and $\mathrm{Cd}$ ) were far beyond standard value, which were 497.1, 2, 1.8, 22.2, and 22.1 times than the standard value, respectively, which showed that the five kinds of metals were mainly concentrated in the local region and their pollution was very serious. The excessive standard rate reflects the degree of excessive standard value. As seen from the excessive standard rate, it can be found that the excessive standard rates of $\mathrm{Sb}, \mathrm{Zn}$, $\mathrm{Pb}$, and $\mathrm{Cd}$ were $100 \%, 50.51 \%, 60.29 \%$, and 53.43\%. All Sb samples exceeded the standard values, indicating that they have posed a serious pollution to the investigated area. $\mathrm{Zn}$ and $\mathrm{Pb}$ had about half of samples exceeding the standard values, of which pollution produced herein was only smaller than those resulting from Sb. Although about half of $\mathrm{Cd}$ samples exceeded the standard values, the $\mathrm{Cd}$ distribution within the investigated area was wider and thus the pollution was not significant. Ni having a smaller excessive standard rate of zero resulted in less pollution. The coefficients of the variation of the six kinds of metals ranged from 0.4 to 0.6 . The spatial variation coefficient of $\mathrm{Sb}$ reached $50.56 \%$, which belonged to strong variation type, suggesting that the spatial distribution of $\mathrm{Sb}$ in surface runoff was extremely uneven and relatively large dispersion. The coefficients of variation of $\mathrm{Cu}, \mathrm{Ni}, \mathrm{Zn}, \mathrm{Cd}$, and $\mathrm{Pb}$ were less than $50 \%$, showing that it had a medium variability, comparatively uniform spatial distribution, and small fluctuations. The kurtosis coefficients of $\mathrm{Sb}, \mathrm{Zn}, \mathrm{Cu}$, and $\mathrm{Pb}$ were between 2.3 and 3. The absolute values of the coefficient of skewness were between 0.0037 and 0.1552 , which is consistent with the normal distribution. The absolute skewness coefficients of $\mathrm{Ni}$ and $\mathrm{Cd}$ were more 


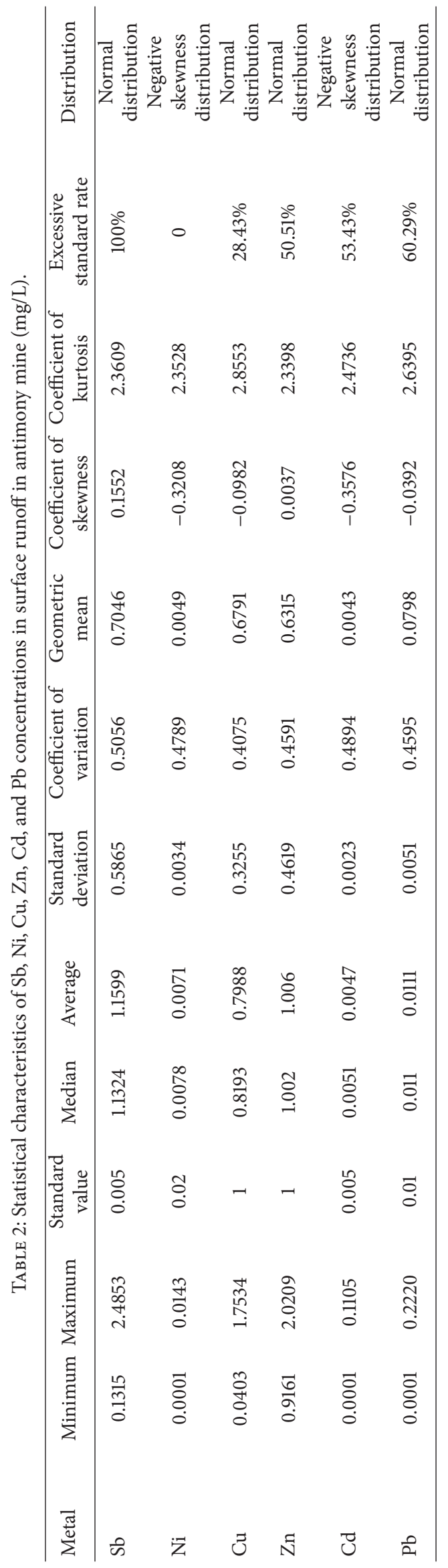


TABLE 3: Theoretical semivariation function model and parameter of $\mathrm{Sb}, \mathrm{Ni}, \mathrm{Cu}, \mathrm{Zn}, \mathrm{Cd}$, and $\mathrm{Pb}$ content of in surface runoff in the antimony mine.

\begin{tabular}{|c|c|c|c|c|c|c|}
\hline Item & Type & $\mathrm{C}_{0}$ & $C_{0}+C$ & $C_{0} /\left(C_{0}+C\right)$ & Variable range $(\mathrm{m})$ & $R^{2}$ \\
\hline $\mathrm{Sb}$ & Spherical & 0.0290 & 0.3780 & 0.0767 & 918 & 0.956 \\
\hline $\mathrm{Ni}$ & Spherical & 0.00000691 & 0.0000139 & 0.504 & 2001 & 0.782 \\
\hline $\mathrm{Cu}$ & Gauss & 0.0601 & 0.1812 & 0.3316 & 1968 & 0.974 \\
\hline $\mathrm{Zn}$ & Spherical & 0.0891 & 0.2022 & 0.5590 & 178 & 0.721 \\
\hline $\mathrm{Cd}$ & Gauss & 0.00000284 & 0.00001147 & 0.248 & 2579 & 0.946 \\
\hline $\mathrm{Pb}$ & Spherical & 0.0000167 & 0.0000681 & 0.245 & 1877 & 0.611 \\
\hline
\end{tabular}

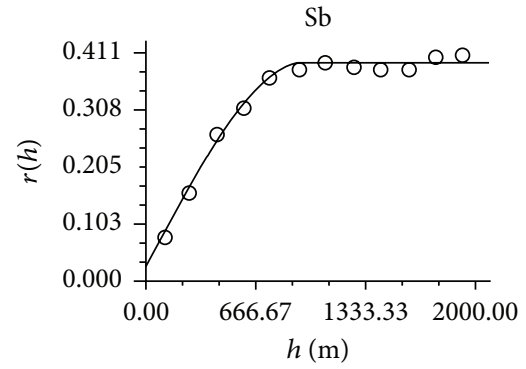

○ Experimental variogram values

_ Theoretical values of variation function

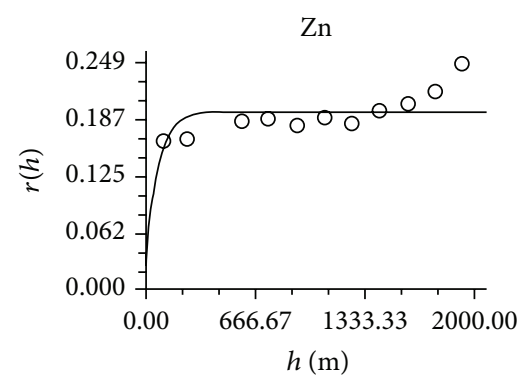

○ Experimental variogram values

_ Theoretical values of variation function

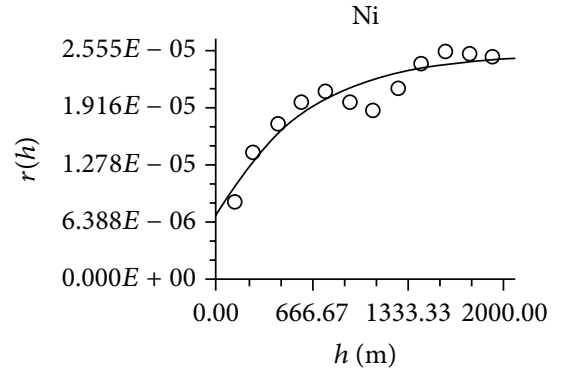

- Experimental variogram values

_ Theoretical values of variation function

$\mathrm{Cd}$

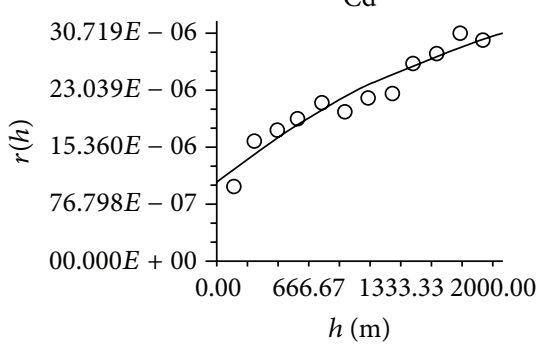

- Experimental variogram values

— Theoretical values of variation function

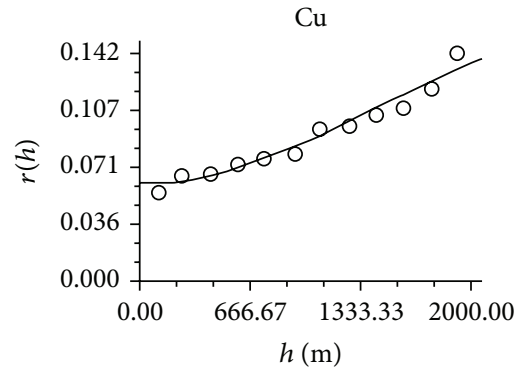

- Experimental variogram values

_ Theoretical values of variation function

Figure 3: Theoretical semivariation function of $\mathrm{Sb}, \mathrm{Ni}, \mathrm{Cu}, \mathrm{Zn}, \mathrm{Cd}$, and $\mathrm{Pb}$ in surface runoff in the antimony mine.

than 0.32 and the coefficients of kurtosis were slightly lower, roughly belonging to the negative skewed distributions. These results demonstrated that the mining, smelting, waste slag stacking and transportation, human activities, and other factors possibly led to the difference in the metal content of the surface runoff in different regions.

\subsection{Spatial Variation of Heavy Metals in Surface Runoff}

3.3.1. Correlation of Spatial Structure. With an effective lag distance of $2 \mathrm{~km}$ and the tolerance angle of $22.5^{\circ}$, the variation functions of those $\mathrm{Sb}, \mathrm{Zn}, \mathrm{Cu}, \mathrm{Pb}$, and $\mathrm{Cd}$ resulting from the surface runoff of antimony mine area were calculated using GS+V9.0 software, respectively. The fitting of the theoretical model of semivariogram was conducted in hope of obtaining the best model as well as parameters (see Table 3 ). The fitting curve of the theoretical semivariation function is shown in Figure 3. As seen from Table 3 and Figure 3, the function fittings for the six kinds of the metals presented better performance, among which the fittings for the $\mathrm{Sb}, \mathrm{Zn}, \mathrm{Ni}$, and $\mathrm{Pb}$ were better by the spherical model, while fittings for $\mathrm{Cu}$, and $\mathrm{Cd}$ were better by the Gauss model. The coefficients of determination were between 0.611 and 0.974 . The rate of nugget value to base sill value $\left(C_{0} /\left(C_{0}+C\right)\right)$ was 0.0767 , closed to zero, indicating that the $\mathrm{Sb}$ in the surface runoff in the investigated area exhibited a strong spatial correlation and its spatial variability was mainly affected by the impact of regional factors, such as soil parent material and climate. $C_{0} /\left(C_{0}+C\right)$ of the $\mathrm{Cd}$ and $\mathrm{Pb}$ were 0.248 and 0.245 , respectively, both of which were less than 0.25 . This showed that the metals have a strong spatial correlation in a contaminated runoff in the investigated area, of which the spatial variability was dominantly affected by the regional factors. In addition, they were influenced by the random factors, such as industrial and agricultural production. $C_{0} /\left(C_{0}+C\right)$ values of the $\mathrm{Ni}$, $\mathrm{Cu}$, and $\mathrm{Zn}$ were $0.504,0.3316$, and 0.559 , respectively, which 

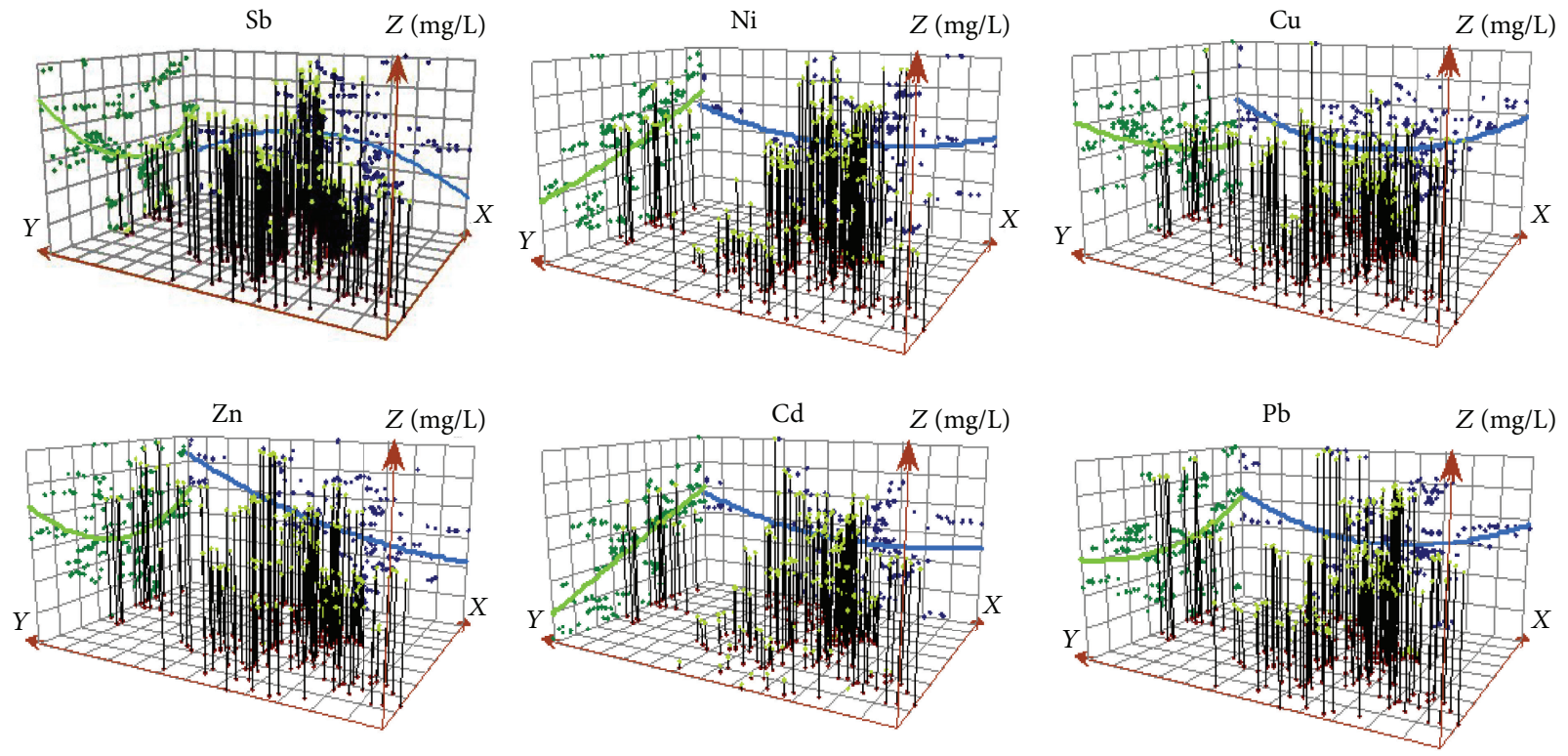

Figure 4: The spatial structures of $\mathrm{Sb}, \mathrm{Ni}, \mathrm{Cu}, \mathrm{Zn}, \mathrm{Cd}$, and $\mathrm{Pb}$ in surface runoff in the antimony mine.

indicated that $\mathrm{Ni}, \mathrm{Cu}$, and $\mathrm{Zn}$ had a moderate correlation degree, and the regional influence on spatial variability was the main factor; however, the impact of the random factor should not be ignored. The difference on the variable ranges of the six kinds of heavy metals was larger, wherein the shortest variable ranges for $\mathrm{Zn}$ were $178 \mathrm{~m}$, which indicated that the spatial correlation within a small area was also strong. The variable range of $\mathrm{Ni}$ and $\mathrm{Cd}$ was $2001 \mathrm{~m}$ and $2579 \mathrm{~m}$, respectively, which exceeded the scope of the investigated area. This implies that a significant drift phenomenon existed. Overall, the six kinds of metals showed an obvious "Nugget Effect."

3.3.2. Feature of Spatial Structure. The spatial distributions of six kinds of the metals were analyzed in ArcGIS software platform; each of the vertical bars represented the concentration (height) and the position of one sample. These points were projected onto one orthogonal plane at east, west direction ( $x$-axis) and north-south direction ( $y$-axis). The optimal fitting line could be obtained through projecting points, through which the concentration at a particular direction could be simulated. The results are shown in Figure 4. As seen from the figure, except the $\mathrm{Sb}$ distribution roughly presenting an inverted " $U$ " shape at north-south direction in blue line, other heavy metals are generally distributed in " $U$ " shape. The Cd distribution showed the inverted " $U$ " shape at eastwest direction in green line, which was opposite to those of the other five kinds of metals. The Sb rapidly increased with north-south edge into the belly. In the investigated area at east-west direction, it showed that, on both sides of the direction, the concentration was higher than that at the middle. For those areas outside the investigated area, there would be a serious pollution by $\mathrm{Sb}$. The distribution of $\mathrm{Zn}$ was similar to that of $\mathrm{Sb}$ at the east and west. The pollution increased along the south to north. There was no stable trend occurring at the end of the curve. This implies that the serious pollution occurred in the northern area. The concentration distribution of $\mathrm{Cu}$ on both sides of direction along north and south was higher than that of middle along north to south. A worsening pollution appeared along west to east. The distribution of $\mathrm{Ni}$, $\mathrm{Pb}$ was similar to that of $\mathrm{Cd}$, which had a uniform distribution with less variation at north and south, while the pollution increased along west to east.

3.3.3. Directional Feature of Spatial Structure. The variability of the six kinds of metals have been calculated using the scientific software Suffer 8.0, and the figures at four directions $\left(0^{\circ}(\mathrm{E} \sim \mathrm{W}), 45^{\circ}(\mathrm{NE} \sim \mathrm{SW}), 90^{\circ}(\mathrm{S} \sim \mathrm{N})\right.$, and $\left.135^{\circ}(\mathrm{SE} \sim \mathrm{NW})\right)$ and four kinds of broken lines were used to reflect the variations at different directions as shown in Figure 5. Figure 5 showed that the variations of $\mathrm{Cu}$ at four directions were approximately coincident, and the variations were almost the same in the step range from $0 \mathrm{~m}$ to $1900 \mathrm{~m}$ and an obvious anisotropy occurred. When the step was beyond $1900 \mathrm{~m}$, the direction difference resulted in the different nugget values at each direction. The longest step range was $1907 \mathrm{~m}$ at $0^{\circ}$ and the shortest step range was $1670 \mathrm{~m}$ at $90^{\circ}$, which all fell within the investigated area. The ratio of the nugget to sill between 0.2516 and 0.3382 showed a good spatial correlation. This also implied that $\mathrm{Cu}$ had a moderate variability within a larger variation range. Different models had different fitting effects for different directions, which indicated that the fitting effect by Gauss model was suitable for $0^{\circ}$ and $90^{\circ}$, while that by the spherical and exponential models was suitable for $45^{\circ}$ and $135^{\circ}$, respectively. The nugget, sill, and variable range values as well as the degree of variation at the direction $\left(0^{\circ}\right)$ are the highest. The fitting results showed that the variations of $\mathrm{Zn}, \mathrm{Ni}, \mathrm{Pb}$, and $\mathrm{Cd}$ at the four directions were approximately coincident; besides, the variation of $\mathrm{Ni}$ was similar to that of $\mathrm{Cd}$ in the step range between $600 \mathrm{~m}$ and $1300 \mathrm{~m}$, and the nugget value of $\mathrm{Zn}$ differed from that of $\mathrm{Ni}$. $\mathrm{Pb}$ had a 

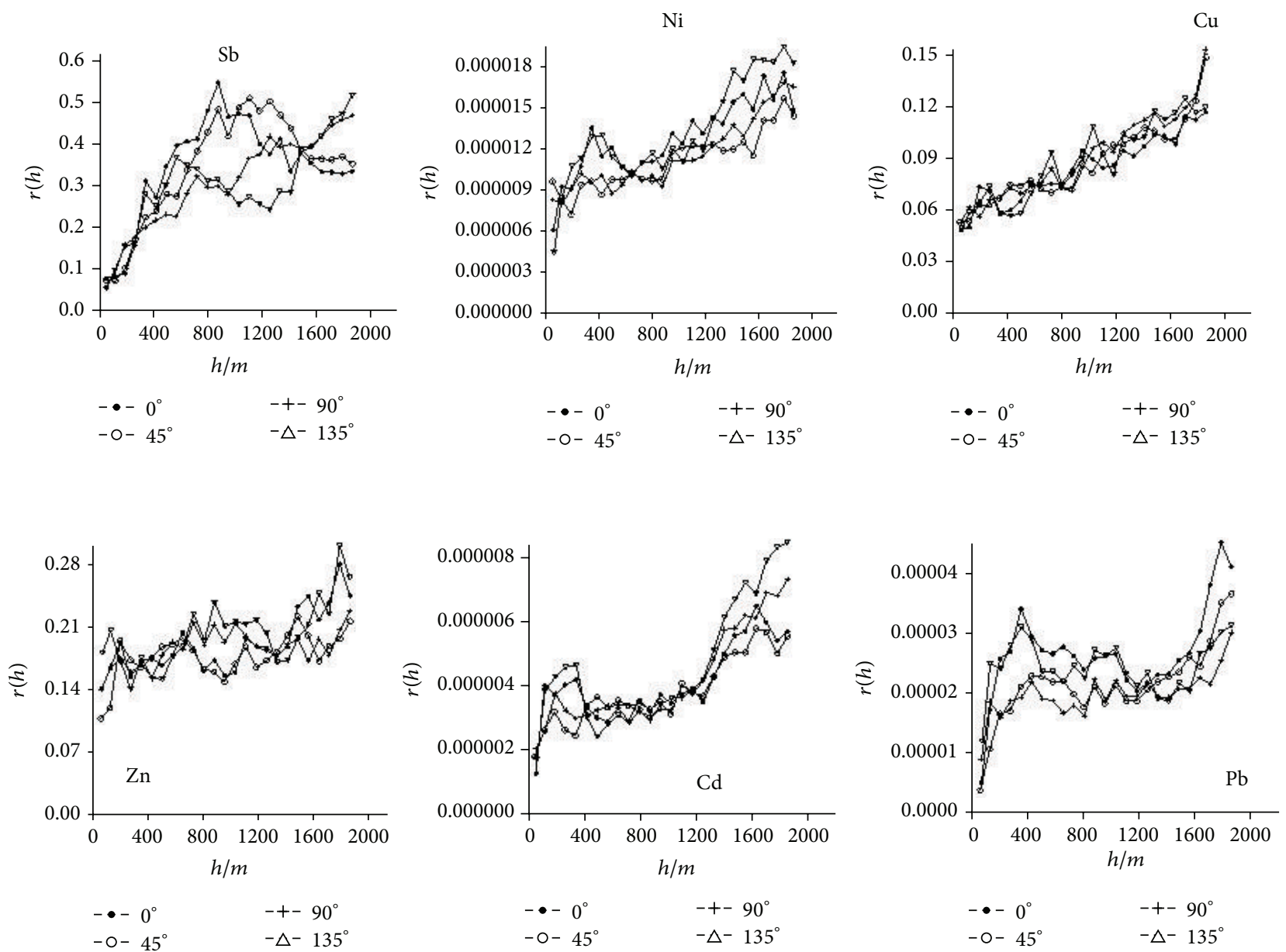

Figure 5: The direction of $\mathrm{Sb}, \mathrm{Ni}, \mathrm{Cu}, \mathrm{Zn}, \mathrm{Cd}$, and $\mathrm{Pb}$ mutation function in surface runoff in the antimony mine.

stronger variability within a wider variation range, which was different from $\mathrm{Cu}$; $\mathrm{Zn}$ had a moderate variability within a smaller variation range; the correlation of $\mathrm{Sb}$ within a smaller variation range was very stronger. The distribution of $\mathrm{Sb}$ showed an obvious anisotropy in the step size of over $300 \mathrm{~m}$, of which the difference was larger. The minimum variable ranges were at $0^{\circ}$ and $90^{\circ}$, while the maximum variable range was $1276 \mathrm{~m}$ at $135^{\circ}$. The ratio value of the nugget to sill that was less than 0.25 could show a good spatial correlation. Gauss model could present a good fitting for $135^{\circ}$, while the spherical model was suitable for other three directions.

\section{Spatial Distribution Characteristics}

Using ArcMap software, the distributions of the six kinds of metals were predicted by an interpolation method as the results shown in Figure 6.

First, from the figure, $\mathrm{Sb}$ was mainly concentrated in the southwest, central part, and northeast in the soil-water interface, forming three primary pollution source. The highest pollution values were in the central part. Combined with the sampling point distribution diagram, it could be seen that the widest area, southwest region, contains two mines, while the middle part and the northeast part contain one, respectively.
The regions with the highest pollution levels roughly fell within those areas in the smelting plants. The concentration was gradually reduced from the middle part to north and south, while the Sb at both ends of the north and south was very low. In the northern zinc plant and southern Zhumu mountain with the Guangjia Ling as the boundary line, the soil-water interface on both ends of region was almost not polluted. This indicated that the pollution from $\mathrm{Sb}$ mainly came from the processes of mining and smelting. The smelting plant is located in the middle of the mine, which led to an enrichment of Sb in the smelting plant.

Second, the distributions of $\mathrm{Cu}$ and $\mathrm{Zn}$ were similar in the soil-water interface. The high concentration pollution was distributed on both sides of southern and northern areas. The low concentration pollution appeared in southeast, like a fan shape. Combined with sample points' distributions, two mines in the Quanqiu Village, a mine in Quanfengaojin and zinc plant in the north of Changlong boundary, form a sector arc shape. The $\mathrm{Zn}$ concentration inside the shape was obviously higher than that outside. Overall, the degree of pollution in the north was larger than that in the south. The regions with the highest concentration contained the zinc plant and station. The surrounding soil-water interface was polluted by waste gas and wastewater from factory through 


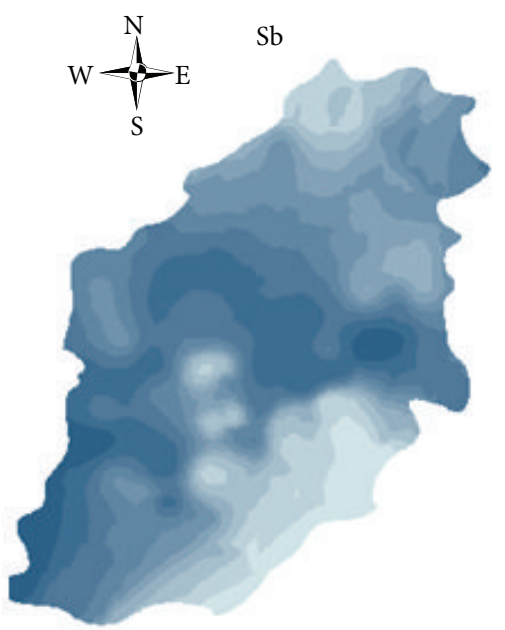

Filled contours
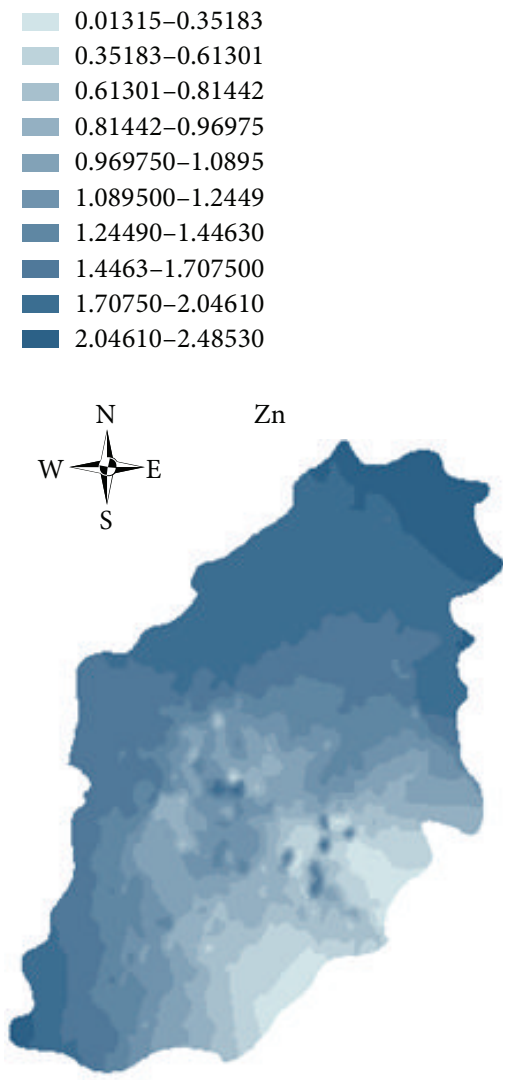

Filled contours

$$
\begin{aligned}
& 0.016140-0.32213 \\
& 0.32213-0.56826 \\
& 0.56826-0.75226 \\
& 0.75226-0.90127 \\
& 0.90127-1.0185 \\
& 1.0185-1.1357 \\
& 1.1357-1.2847 \\
& 1.2847-1.4741 \\
& 1.4741-1.7149 \\
& 1.7149-2.0208
\end{aligned}
$$

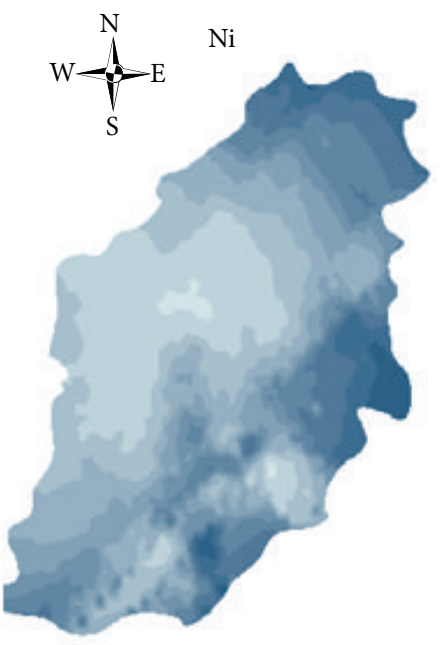

Filled contours

$$
\begin{aligned}
& 0.0000-0.00254 \\
& 0.00254-0.00450 \\
& 0.00450-0.00601 \\
& 0.00601-0.00718 \\
& 0.00718-0.00808 \\
& 0.00808-0.00877 \\
& 0.00877-0.00967 \\
& 0.00967-0.01083 \\
& 0.01083-0.01235 \\
& 0.01235-0.01431
\end{aligned}
$$

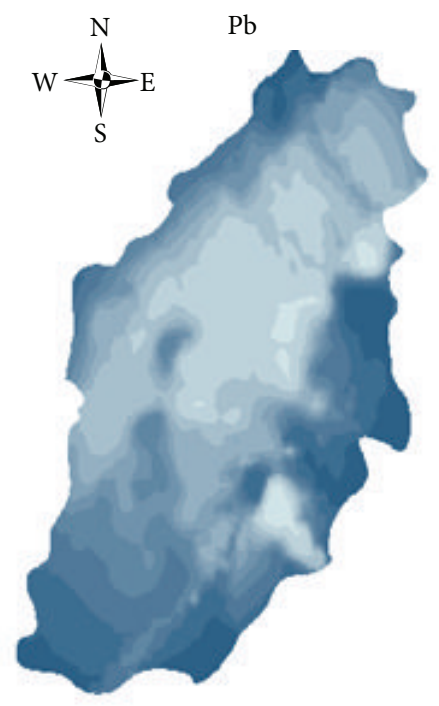

Filled contours

$$
\begin{aligned}
& 0.0001-0.00452 \\
& 0.00452-0.00737 \\
& 0.00737-0.00921 \\
& 0.00921-0.01039 \\
& 0.01039-0.01115 \\
& 0.01115-0.01191 \\
& 0.01191-0.01309 \\
& 0.01309-0.01493 \\
& 0.01493-0.01778 \\
& 0.01778-0.02220
\end{aligned}
$$

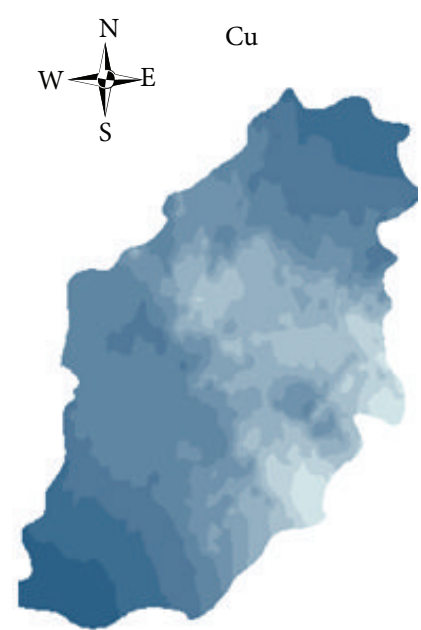

Filled contours

$$
\begin{aligned}
& 0.040273-0.27497 \\
& 0.27497-0.45596 \\
& 0.45596-0.59554 \\
& 0.59554-0.70318 \\
& 0.70318-0.78618 \\
& 0.78618-0.89382 \\
& 0.89382-1.0334 \\
& 1.0334-1.2144 \\
& 1.2144-1.4491 \\
& 1.4491-1.7534
\end{aligned}
$$

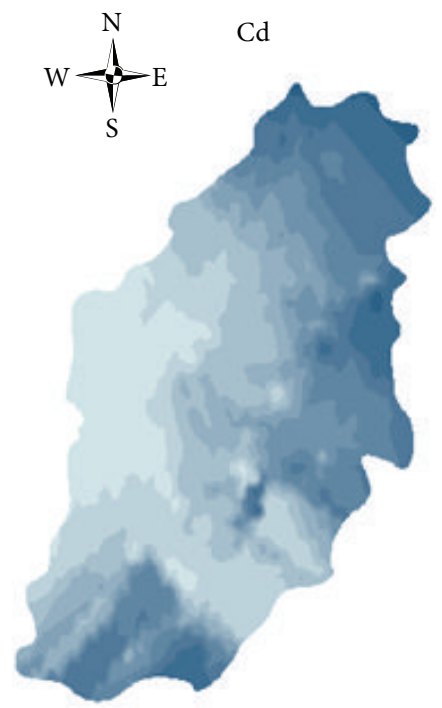

Filled contours

$$
\begin{aligned}
& 0.00005-0.00215 \\
& 0.00215-0.00355 \\
& 0.00355-0.00450 \\
& 0.00450-0.00513 \\
& 0.00513-0.00555 \\
& 0.00555-0.00598 \\
& 0.00598-0.00661 \\
& 0.00661-0.00755 \\
& 0.00755-0.00896 \\
& 0.00896-0.01105
\end{aligned}
$$

Figure 6: The predicted map of spatial distribution of $\mathrm{Sb}, \mathrm{Ni}, \mathrm{Cu}, \mathrm{Zn}, \mathrm{Cd}$, and $\mathrm{Pb}$ in surface runoff in the antimony mine with $\mathrm{Kriging}$ interpolation. 
the hydrological cycle. The car tires, instrumentation, and organic compounds consisted of $\mathrm{Zn}$ and $\mathrm{Cu}$. Thus, $\mathrm{Cu}$ and $\mathrm{Zn}$ in the pollution flow of the soil-water interference were expected to be primarily related to transportation, mining, and industrial activities in the investigated area. The pollution caused by those industrial activities and transportation to surrounding soil-water interface was much more serious than that by the mining activities.

Finally, the distributions of $\mathrm{Ni}, \mathrm{Pb}$, and $\mathrm{Cd}$ were similar in the interface of soil-water. These metals were mainly located in the northwest and southeast and distributed in the strip, while their concentrations tested in this study were very low in the southwest and northeast. The higher pollution levels were concentrated in Kuangshan country, Jiangda bay, and east of Huanggang Village. Their distributions were present in " $U$ " shape at south-north direction and flat curve at west-east direction. Combined with the distributions of sampling points, the high pollution in the north fell within the residential district, station, and zinc plant; the high pollution in the east fell with the smelting plant; the high pollution in south fell with the residential district. The content of $\mathrm{Ni}$ was higher in alloy, electronic products, which mainly resulted from industry and infiltration and deposition of waste from mining. The $\mathrm{Pb}$ as an important material resulting from lead storage battery, alloy, pipe and cable, factory waste, and automobile exhaust presented a relatively higher content. The mining and smelting processes are also found to be an important source of $\mathrm{Pb}$. Cd is an important material, which is produced by alloys, batteries, electronic products, and household appliances. There was a higher concentration in the waste of ore mining and industrial smelting. Therefore, the pollution of the three kinds of metals in the soil-water interface in the north would come from three aspects including the transportation, industry, and living activities. The pollution with high level in the east resulted from mining, smelting process and that in the south resulted from waste electronic products, household appliances, building materials, electroplating, and other types of living garbage.

\section{Conclusions}

In this study, the spatial variability and distributions of the metals in surface runoff in a nonferrous metal mine were investigated. The spatial distribution of the $\mathrm{Sb}$ in surface runoff in the investigated area was very uneven and relatively large dispersion. The coefficients of variation of $\mathrm{Cu}, \mathrm{Ni}, \mathrm{Pb}$, $\mathrm{Cd}$, and $\mathrm{Cu}$ were less than $50 \%$, indicating a medium variability, uniform spatial distribution, and comparatively small fluctuations. Except the $\mathrm{Ni}$ concentration lower than the standard value, the maximum values of other five metals ( $\mathrm{Sb}$, $\mathrm{Zn}, \mathrm{Cu}, \mathrm{Pb}$, and $\mathrm{Cd}$ ) exceeded the standard values, which were 497.1, 2, 1.8, 22.2, and 22.1 times than the standard values, respectively. In addition, for all samples, the $\mathrm{Sb}$ concentrations were all over the standard values and for over half of the samples, $\mathrm{Zn}, \mathrm{Pb}$, and $\mathrm{Cd}$ exceed the standard values, while the Ni did not exceed the standard range. This showed that except $\mathrm{Ni}$, the other five kinds of metals were the dominant pollution sources. The spatial structure characteristics of the six kinds of metals in soil-water interface pollution flow were analyzed. $\mathrm{Sb}, \mathrm{Zn}, \mathrm{Ni}$, and $\mathrm{Pb}$ could be well fitted by the spherical model, and the $\mathrm{Cd}$ and $\mathrm{Cu}$ could be well fitted by Gauss model. The determination coefficients of the fitting model $\left(R^{2}\right)$ were between 0.721 and 0.976 , respectively, while the rate of nugget to sill value range from 0.0767 to 0.559 suggested that the six metals had a strong spatial correlation. The pollution distributions of $\mathrm{Ni}, \mathrm{Pb}$, and $\mathrm{Cd}$ were similar in the interfacial contamination of the soil-water, which was mainly concentrated in the ends of north and south and the east. The main reasons for contamination were attributed to residents living, transportation, and industrial activities. The distribution of $\mathrm{Sb}$ was mainly concentrated in the middle, resulting from smelting plant, mining, and industrial activities. The pollution distribution of $\mathrm{Zn}$ was similar to $\mathrm{Cu}$, mainly concentrated on ends of the north and south and the west, of which the location fell within the mine, zinc plant, residential area, and traffic busy area. This indicated that the metals came from a wide range of sources.

\section{Competing Interests}

The authors declare that they have no competing interests.

\section{Acknowledgments}

This research was supported by the National Natural Science Foundation of China (nos. 41472328 and 51174090).

\section{References}

[1] R. Bozhi, M. Hongpu, Z. Xie et al., "Spatial structure characteristics of heavy metal content and pollution levels of rainfall runoff in manganese ore zone," Journal of Environmental Science, vol. 34, no. 7, pp. 1730-1737, 2014.

[2] G. Ungureanu, S. Santos, R. Boaventura, and C. Botelho, "Arsenic and antimony in water and wastewater: overview of removal techniques with special reference to latest advances in adsorption," Journal of Environmental Management, vol. 151, pp. 326-342, 2015.

[3] C. Pérez-Sirvent, M. J. Martínez-Sánchez, S. Martínez-López, and M. Hernández-Córdoba, "Antimony distribution in soils and plants near an abandoned mining site," Microchemical Journal, vol. 97, no. 1, pp. 52-56, 2011.

[4] K. H. Cho and M.-H. Park, "Prioritizing subwatersheds for stormwater pollution to wachusett reservoir," Water Environment Research, vol. 85, no. 2, pp. 158-166, 2013.

[5] J. Kim and H. Furumai, "Assessment of rainwater availability by building type and water use through GIS-based scenario analysis," Water Resources Management, vol. 26, no. 6, pp. 14991511, 2012.

[6] C. Tao, C. Qingrui, L. Jing et al., "Pollution and potential environment risk assessment of soil heavy metals in sewage irrigation area," Journal of Agro-Environment Science, vol. 31, no. 11, pp. 2152-2159, 2012.

[7] L. Li, C. Gao, Y.-Y. Dong, S.-S. Li, and Y. Wang, "Soil heavy metal pollution assessment in typical coal industry park of Henan Province," Chinese Journal of Soil Science, vol. 44, no. 1, pp. 205209, 2013.

[8] C. Xingtao, L. Wenlou, G. Haiquan et al., "Assessment of the heavy metal pollution and the potential ecological hazard in 
urban soil of Shijiazhuang City," Geoscience, vol. 25, no. 1, pp. 169-175, 2011.

[9] J. B. Campbell, "Spatial variation of sand content and $\mathrm{pH}$ within single contiguous delineations of two soil mapping units," Soil Science Society of America Journal, vol. 42, no. 3, pp. 460-464, 1978.

[10] Y. Zhu, H. Liu, and X. Jiang, "Investigation of the spatial variability of nitrogen and phosphorus in purple soils in Jiangjing City, Sichuan, China," Environmental Science, vol. 25, no. 1, pp. 138-143, 2004.

[11] J.-T. Peng, G.-S. Li, W.-L. Fu, X.-S. Yi, J.-C. Lan, and B. Yuan, "Temporal-spatial variations of total nitrogen in the degraded grassland of Three-River Headwaters region in Qinghai Province," Environmental Science, vol. 33, no. 7, pp. 24902496, 2012.

[12] X.-L. Liu, H.-L. Qin, W.-X. Wei, J.-S. Wu, C.-H. Wang, and Y. $\mathrm{Li}$, "Spatial variability of available nutrients in a vegetable soil in Changsha," Chinese Journal of Soil Science, vol. 42, no. 4, pp. 833-840, 2011.

[13] M. Herbst and B. Diekkrüger, "Modelling the spatial variability of soil moisture in a micro-scale catchment and comparison with field data using geostatistics," Physics and Chemistry of the Earth, vol. 28, no. 6-7, pp. 239-245, 2003.

[14] L. Brocca, R. Morbidelli, F. Melone, and T. Moramarco, "Soil moisture spatial variability in experimental areas of central Italy," Journal of Hydrology, vol. 333, no. 2-4, pp. 356-373, 2007.

[15] Y. Zhan, X. Jiang, C. Chen et al., "Spatial distribution characteristics and pollution assessment of heavy metals in sediments from the southwestern part of Taihu Lake," Research of Environmental Sciences, vol. 24, no. 4, pp. 364-369, 2011.

[16] Y.-L. Liu, L.-J. Zhang, X.-F. Han, T.-F. Zhuang, Z.-X. Shi, and X.-Z. Lu, "Spatial variability and evaluation of soil heavy metal contamination in the urban-transect of Shanghai," Environmental Science, vol. 33, no. 2, pp. 599-605, 2012.

[17] X. Ma, J. Qing, and L. Feng, "Chemical fractions and bioavailability of heavy metals in long-term sewage-irrigated soils," Chinese Agricultural Science Bulletin, vol. 26, no. 22, pp. 318-322, 2010.

[18] X. Huang, X. Zhu, L. Tang, and H. Ji, "Pollution characteristics and their comparative study of heavy metals in the gold and iron mine soil of the upstream area of Miyun Reservoir, Beijing," Acta Scientiae Circumstantiae, vol. 32, no. 6, pp. 1520-1528, 2012.

[19] R. Shi, Q. Zhou, Y. Cai, and H. Zhang, "Contamination characteristics and source analyses of PAHs in contaminated flows from soil-water interfaces of Tianjin Suburban Areas, China," Acta Scientiae Circumstantiae, vol. 30, no. 4, pp. 874$881,2010$.

[20] W. Wu, S. Yin, H. Liu et al., "Spatial structure and distribution characteristics of soil heavy metals in wastewater irrigation district," Transactions of the Chinese Society of Agricultural Engineering, vol. 29, no. 4, pp. 165-170, 2013.

[21] Z. Hailong, C. Jie, D. Wenjing et al., "Assessment of soil heavy metals pollution in the chemical industrial areas of Nanjing peri-urban zone," Acta Scientiae Circumstantiae, vol. 25, no. 9, pp. 1182-1188, 2005.

[22] X. Li, T. Chen, M. Lei et al., "Accumulation of heavy metals in urban soils under different land uses in Beijing," Acta Scientiae Circumstantiae, vol. 30, no. 11, pp. 2285-2293, 2010.

[23] Y. Li, L. Xu, X. Xiong et al., "The spatial structure feature of heavy metals in agricultural soil of mining city: a case study of Fuxin, China," Acta Scientiae Circumstantiae, vol. 27, no. 4, pp. 680-687, 2007.
[24] B. Ren, K. Liu, H. Ma, H. Zhou, and X. Zheng, "Analysis of manganese pollution load of rainfall runoff in manganese ore zone based on SWAT model," Environmental Pollution \& Control, vol. 36, no. 11, pp. 50-54, 2014.

[25] Y. Liu and G. Wei, “The improvement method of Grubbs Test in clinical laboratory's internal quality control," Henan Science, vol. 124, no. 5, pp. 642-645, 2006.

[26] Q. Liu, H. Zang, and Y. Shi, "Assessment and spatial distribution of heavy metals on the surface of small scale farmland in Yanggu County, Shandong Province," Surface Bulletin, vol. 40, no. 3, pp. 673-678, 2009.

[27] F. Liu, X. Shi, X. Pan, and D. Yu, "Characteristics of spatial variability of total phosphorus in soil of the typical area of Taihu Lake Watershed," Scientia Geographica Sinica, no. 1, pp. 77-81, 2003.

[28] W. Jun, "Assessment paper of 'medical imaging technology' teaming form SPSS17.0 sofeware's normal P-P plots," Modern Instruments, vol. 18, no. 2, pp. 45-47, 2012.

[29] L. Aiyu, An Introduction to SPSS, Renmin Press, Shanghai, China, 2007.

[30] T. Guoan and Y. Xin, (ArcGIS) Experimental Course of Spatial Analysis of GIP, Science Press, Beijing, China, 2006. 

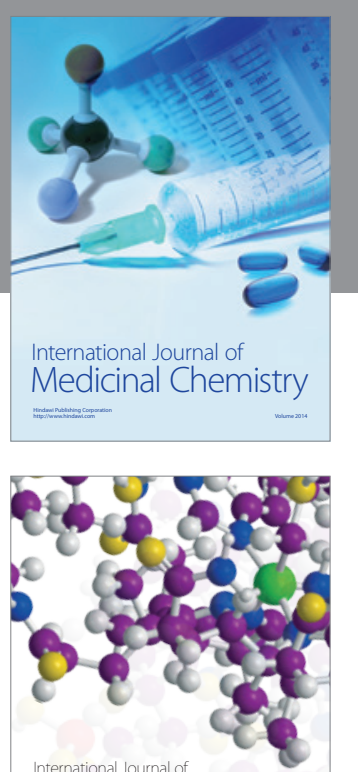

Carbohydrate Chemistry

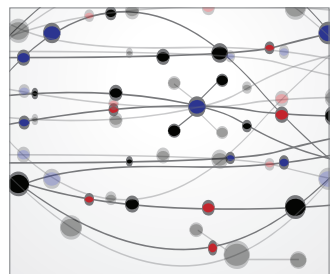

The Scientific World Journal
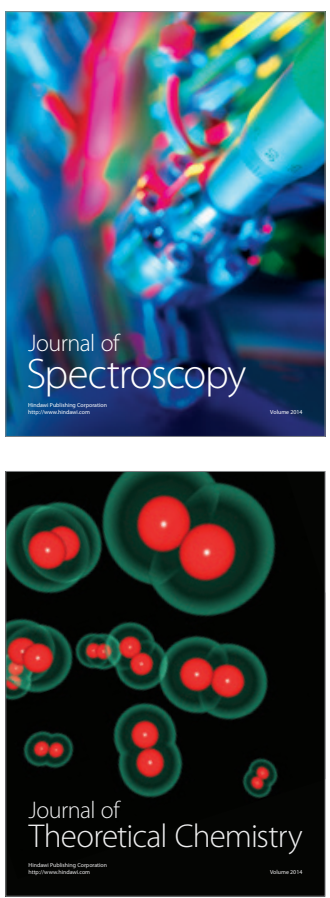
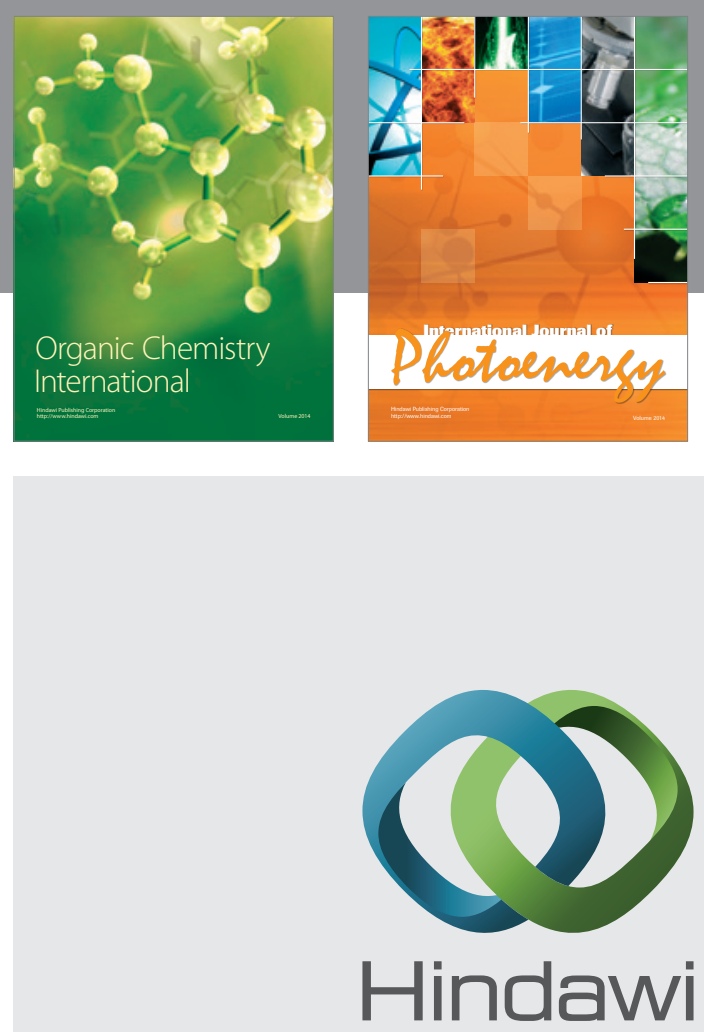

Submit your manuscripts at

http://www.hindawi.com

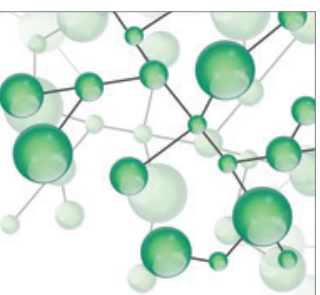

International Journal of

Inorganic Chemistry

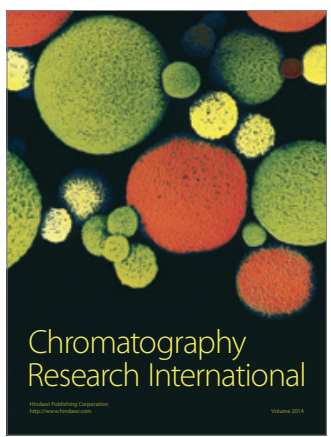

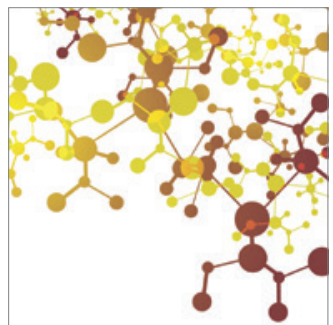

Applied Chemistry
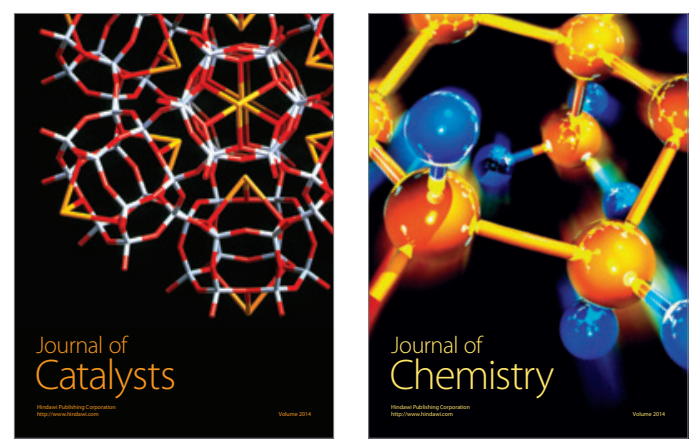
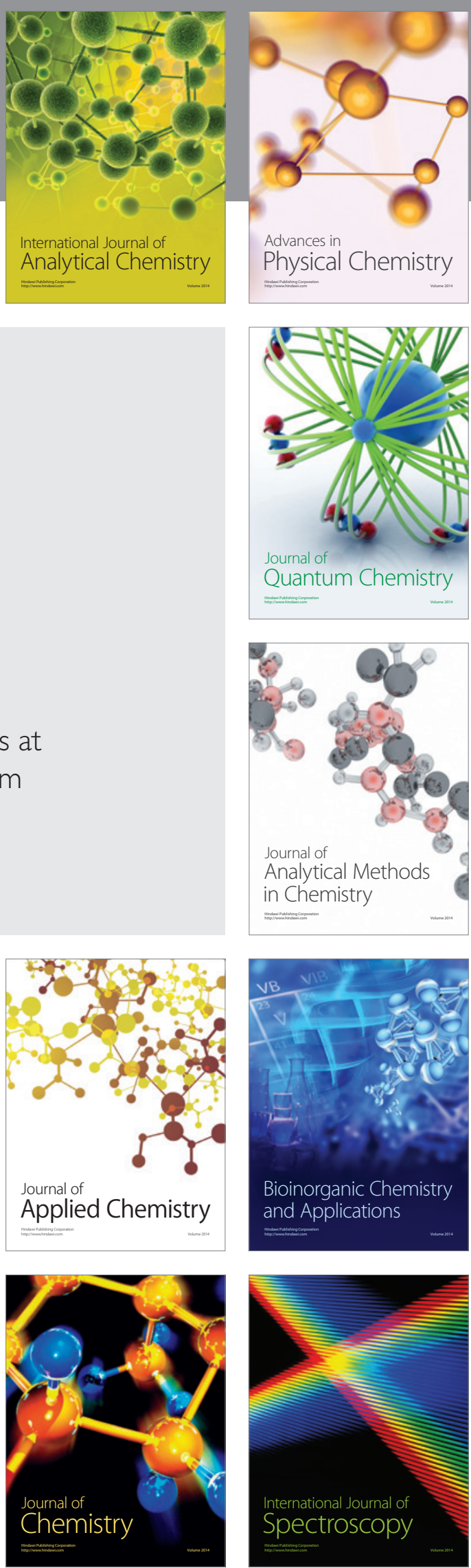